\title{
REGULATORY RATIONING: A SOLUTION TO HEALTH CARE RESOURCE ALLOCATION
}

\author{
ROBERT H. BLANK†
}

\section{INTRODUCTION}

Despite all the recent controversy, rationing has always been a part of medical decision making. Figure I presents a spectrum of ways in which health care can be rationed. Whether imposed by a market system in which price determines access, a triage system where care is distributed on the basis of need defined largely by the medical community, or a queue system in which time and the waiting process become the major rationing device, medical resources have always been distributed according to criteria that contain varying degrees of subjectivity. In almost all instances, rationing criteria are grounded in a particular value context that results in an inequitable distribution of resources based on social as well as strictly medical considerations.

In addition to illustrating the range of rationing options for health care, Figure I introduces yet another complexion in defining the concept. Some forms of rationing infer or necessitate government involvement, either direct or indirect, while others fail to distinguish between private and public sector choices. This distinction is critical to a clarification of how current health care options differ from past ones. Less explicit forms of rationing toward the top of the figure are no longer sufficient to resolve health care dilemmas in this era. As a result, we are now witnessing a shift toward the bottom end of the spectrum, possibly culminating in a central role for the government in the rationing of increasingly scarce medical resources. Although explicit rationing under the authority of the government is but one form of rationing, there appear to be many forces that, concurrently, are moving American society in that direction. At the same time, however, explicit public rationing is feared by some observers, who suggest that rationing is unnecessary or an anathema to be avoided at all costs. ${ }^{1}$

† Senior Lecturer in Political Science, University of Canterbury, Christchurch, New Zealand. Purdue University, A.B. 1965; University of Maryland, M.A. 1969, Ph.D. 1971.

${ }^{1}$ See Arthur L. Caplan, How Should Values Count in the Allocation of New Technologies in Health Care?, in IN SEARCH OF EQUITY: HEALTH NEEDS AND THE HEALTH CARE SYSTEM 95, 97 (Ronald Bayer et al. eds., 1983) (noting that the health 


\section{FIGURE I}

FORMS OF HEALTH CARE RATIONING

\begin{tabular}{||l|l||}
\hline \multicolumn{1}{|c|}{ FORM } & \multicolumn{1}{|c|}{ CRITERIA USED } \\
\hline \hline Physician Discretion & $\begin{array}{l}\text { Medical benefit to patient } \\
\text { Medical risk to patient } \\
\text { Social class or mental capacity }\end{array}$ \\
\hline $\begin{array}{l}\text { Competitive } \\
\text { Marketplace }\end{array}$ & Ability to pay \\
\hline $\begin{array}{l}\text { Insurance } \\
\text { Marketplace }\end{array}$ & $\begin{array}{l}\text { Ability to pay for insurance } \\
\text { Group membership } \\
\text { Employment }\end{array}$ \\
\hline $\begin{array}{l}\text { Socialized Insurance } \\
\text { (i.e., Medicaid) }\end{array}$ & $\begin{array}{l}\text { Entitlement } \\
\text { Means test }\end{array}$ \\
\hline Legal & Litigation to gain access \& treatment \\
\hline $\begin{array}{l}\text { Personal Fundraising } \\
\text { Implicit rationing }\end{array}$ & $\begin{array}{l}\text { Support of social organizations } \\
\text { Skill in public relations } \\
\text { Willingness to appeal to public }\end{array}$ \\
\hline Controlled Rationing & $\begin{array}{l}\text { Queuing } \\
\text { Limited manpower \& facilities } \\
\text { Medical benefits to patient with } \\
\text { consideration of social costs }\end{array}$ \\
\hline Explicit Rationing & $\begin{array}{l}\text { Triage } \\
\text { Medical benefits to patient with } \\
\text { emphasis on social costs and } \\
\text { benefits }\end{array}$ \\
\hline $\begin{array}{l}\text { Government control of medicine } \\
\text { Equity in access to primary care } \\
\text { Social benefit over specific patient } \\
\text { benefits } \\
\text { Cost to society }\end{array}$ \\
\hline
\end{tabular}

Instead of focusing on whether some form of rationing is necessary, the debate should be directed toward the extent to which the government and its agents ought to take a direct role in establishing rationing procedures and structure. Should the

care crisis is largely an artifact of quantification techniques such as cost benefit analysis); see also RITA RICARDO-CAMPBELL, THE ECONOMICS AND POLITICS OF HEALTH 266-86 (1982) (explaining that the major problem in health care today is overregulation); Norman G. Levinsky, Age as a Criterion for Rationing Health Care, 322 NEW ENG. J. MED. 1813, 1814 (1990). 
haphazard, inequitable, and often contradictory private rationing continue, or should the government accept responsibility for the allocation and use of medical resources and take active steps to design and implement a comprehensive rationing system? I argue that the government has this responsibility and must soon act upon it if a health care crisis is to be averted.

Despite the strong antipathy toward the concept of rationing in the United States, the rationing of medical technologies will become more prevalent and explicit. ${ }^{2}$ George Annas is correct in suggesting that the customary approach to rationing medicine, which is practiced by health care providers but not explicitly acknowledged, gives us the illusion that we do not have to make these choices, but it does so only at the cost of mass deception. ${ }^{3}$ This deception, in turn, has contributed to the misconception that as a society we can avoid explicit rationing decisions because we have managed to do so thus far. Some observers still argue that there is no need to deny even the best medical technology to anyone if only we eliminate unnecessary services and facilities. ${ }^{4}$ It is natural, when faced with such painful choices, to take solace in approaches that appear to free us from those decisions. It is becoming increasingly clear, however, that American society can no longer dodge the problems of rationing. Although some persons remain content with the illusions of the customary approach, high technology medicine accompanied by the array of demographic and social trends, including an aging population and heightened public demands, make that impossible. ${ }^{5}$

2 See Robert H. BLANK, RATIONING MEdicine 26-27 (1988); see also DANIEL Callahan, SETting Limits: MEdical GoAls IN AN AGING Society 123-26 (1987) (discussing the "inevitability" of the need for rationing decisions and the near certainty that "demand for health care will . . . outstrip available resources"); PAUL T. Menzel, Strong Medicine: The Ethical Rationing of Health Care 3-19 (1990) (offering justifications of rationing on economic efficiency grounds).

${ }^{3}$ See George J. Annas, The Prostitute, the Playboy, and the Poet: Rationing Schemes for Organ Transplantation, 75 AM. J. PuB. HEALTH 187, 187 (1985) (stating that the decision by Congress in 1972 to fund kidney treatment simply postponed the time when identical decisions had to be made about candidates for heart and liver transplants).

4 See Arnold S. Relman, Is Rationing Inevitable?, 322 NEw ENG. J. MED. 1809, 1810 (1990).

${ }^{5}$ Elderly persons are the leading users of hospital care and have the highest per capita expenditures for health care. See INSTITUTE OF MEDICINE, EXTENDING LifE, ENHANCING LIFE: A NATIONAL RESEARCH AGENDA ON AgING 7 (Edmund T. Lonergan ed., 1991). In 1987 the cost to provide health care for elderly patients was $\$ 162$ billion, or $\$ 5360$ per capita. See $i d$. By the year 2040, middlerange estimates suggest 
The most appropriate question today is not whether rationing ought to be done (it always has been) but, rather, what form it should take and how we can establish equitable and reasonable procedures. To this end, a public dialogue over societal goals and priorities that includes consideration of the preferred agents for rationing medical resources must be initiated. This initial enterprise could take the form of Lester Milbrath's Council for Long Range Societal Guidance, a standing government commission, or other proposed mechanisms. ${ }^{6}$

Although a consensus on how medical resources ought to be distributed is unlikely, it may be possible to reach general agreement on the procedures through which society will approach these problems. If we can agree that the decisional criteria are fair and understand that we are bound by them, specific applications, although difficult, might be perceived as unfortunate rather than unfair. One of the reasons individuals and health care providers tend to reject the notion of rationing or any attempt to withhold treatment is that there is no guarantee that the resources not allocated will be used fairly or even more efficiently. If one person forgoes a needed liver transplant, the beneficiary of the rationing will probably be someone else who will have the transplantsomeone perhaps who is less "deserving."

that the elderly population will more than double in size. See Edward L. Schneider \& Jack M. Guralnik, The Aging of America: Impact on Health Care Costs, 263 JAMA 2335, 2337 (1990). Persons over 85 now constitute about one-sixth of the total elderly, a proportion that is increasing in part because of the intensive expenditure for medical care during that stage of life; it is estimated that by the year 2010 the number of elderly aged 85 and over will increase by about $50 \%$. See id. "By 2040, the average age of a baby boomer will be 85 years, and the level of Medicare spending for the population 65 years and above could range from $\$ 147$ to $\$ 212$ billion (in 1987 dollars)." Id.

6 See LESTER W. MILbRATH, ENVISIONING A SUSTAINABLE SOCIETY: LEARNING OUR WAY OUT 288-96 (1989) (recommending the creation of a council that ensures longrange future planning because existing governmental institutions are too busy with urgent problems). The Milbrath Council, a part of national government, would engage in long-range forecasting and develop possible future scenarios. See id. at 289. It would also monitor conditions and changes in society, facilitate social learning, enhance citizen dialogue and thinking about the issues, and make recommendations to public officials based on thorough research and deep thought. Milbrath conceives of the council as composed of twenty-one generalists who have demonstrated a high capacity of thinking about broad social issues. These generalists, however, would be aided by two or more competing forecasting teams and adequate staffing to ensure an open flow of information and ideas. See $i d$. at 293.

${ }^{7}$ See Norman Daniels, Why Saying No to Patients in the United States is So Hard: Cost Containment, Justice, and Provider Autonomy, 314 NEW ENG. J. MED. 1380, 1383 (1986). 
This Article proceeds by first examining the value context which includes a strong emphasis on individual lifestyle choice even when it leads to ill health, the right to unlimited health care, and the unrealistic dependence on technology to fix our health problems. Because this value system so effectively works against setting limits, constraints must be imposed from outside. This Article then reviews the marketplace approach which many observers support and finds it lacking. The intensifying health care crisis within the context of this fragmented combination of private-public funding, it is argued, calls for a more systematic regulatory approach if we are to have an equitable, efficient, and workable rationing system. Although it is unlikely that the single payer regulatory model presented here will fully resolve this crisis, the time is ripe for a comprehensive, and controversial, move toward a national-level, regulatory approach.

\section{The Liberal Values SySTEM: RightS vs. Responsibility}

\section{A. Individual Rights}

Among the major difficulties in establishing a workable rationing system in the United States are the deeply imbedded values that oppose setting limits to health care. Americans depend heavily on the liberal tradition and emphasize individual autonomy, self-determination, and a shared belief in the value of the individual; individuals ought to be free to determine their preferred lifestyle and then, as long as they do not directly harm others, to live it, even if it is self-destructive. Within this value context, even the suggestion that individuals have a responsibility to live a healthy life for their own good and that of the community is attacked as "victim blaming" or "blatant paternalism" and contrary to individual choice. The shift in the burden of disease, from infectious diseases that required major societal efforts to control toward diseases linked to individual behavior, presents a serious challenge to this value of lifestyle choice, however. For instance, the Secretary of the Health and Human Services, Louis Sullivan, concludes that " [b]etter control of fewer than ten risk factors . . . could prevent between 40 and 70 percent of all premature deaths, a third of all cases of acute disability, and two thirds of all cases of chronic disability. ${ }^{n}$ The

${ }^{8}$ Louis W. Sullivan, Healthy People 2000, 323 NEW ENG.J. MED. 1065, 1066 (1990). 
obstacle that any strategy of risk control faces is the radical change that would be required in many individuals' behavior.

In addition to placing a high priority on individual lifestyle choice, American society heavily emphasizes the individual's right to medical care. Even if in the aggregate we are willing to cut costs, when it comes to the individual patient, we often expend all available resources without consideration of cost. There is a not-soimplicit assumption that every person has a right to unlimited expenditure on his/her behalf, despite our knowledge that in the aggregate this is not feasible. ${ }^{9}$ The problem of unlimited individual claims in the context of limited societal resources has produced the present health care dilemma.

Further complications arise because the distribution of medical resources is skewed toward a very small proportion of the population. Increasingly, medical resources have been concentrated on a relatively small number of patients in acute care settings. In 1980, $13 \%$ of the patients in a study accounted for as much hospital billing as the other $87 \%$, and the most costly $10 \%$ of patients consumed between $42 \%$ and $47 \%$ of total billings. ${ }^{10}$ Substantial questions about the just distribution of scarce societal resources are thereby accentuated in the establishment of biomedical priorities.

The emphasis on the individual's right to medical care is also reflected in the patient-physician relationship, which is viewed largely as a private one, beyond the public realm. Supposedly, this relationship is immune from economics and reflects a technological imperative, where technologies are to be used even if they are of marginal or questionable benefit to the patient. This relationship, combined with the value of individual rights and a great faith in the power of technology, makes patients likely to go to court when anything goes wrong. In turn, this pattern leads to the practice of defensive medicine and an even greater reliance and utilization of sophisticated and expensive diagnostic tests, some of which offer

${ }^{9}$ See Harvard Community Health Plan, The LORAN Commission: A Report to the Community, in 1 EMERGING ISSUES IN BIOMEDIGAL POLICY 64, 77 (Robert H. Blank \& Andrea L. Bonnicksen eds., 1992) (finding that in response to a question in the survey conducted for the commission, over $90 \%$ of the respondents agreed that "everyone should have the right to the best possible medical care-as good as the treatment a millionaire gets" and that $51 \%$ "refused to set any monetary limit-even up to $\$ 5$ million-on what should be spent in the attempt to save a life").

${ }^{10}$ See Christopher J. Zook \& Francis D. Moore, High-Cost Users of Medical Care, 302 NEW ENG. J. MED. 996, 997 (1980). 
little proven efficacy. Moreover, a few highly publicized megasettlements reinforce expectations and escalate this cycle.

\section{B. Technology: High Demand E High Cost}

Americans are also predisposed toward progress through technological means. We have developed an unrealistic dependence on technology to fix our health problems at the expense of preventive health care approaches. In our value system it is arguably easier to look for the quick technological fix than it is to alter individual behavior to prevent disease, or at least to reduce the risk, in the first place. As a society, we have come to expect the best that medical science can offer for ourselves and our loved ones. ${ }^{11}$

These public expectations and perceptions of medicine have resulted in an over-utilization of, and reliance on, technology in American medical practice. Patients demand access to the newest technologies because they are convinced of their value. Popular health-oriented magazines and television shows extol the virtues of medical innovations. Physicians have been trained in the technological imperative, which holds that a technology should be used despite its cost if it offers any possibility of benefit.

Although we complain about the high cost, when our health is at stake, we expect no expense to be spared. The preferred solution for many consumers is simply to shift the basis of payment to the government or private third-party payers. These demands clearly prevent any simple solution to the problems of health care.

Reinforcing this maximalist approach to medical care, we have created a complicated array of mechanisms for minimizing the amount any single individual will pay for these benefits. Private health insurance allows individuals to protect themselves by spreading the risk of expensive medical treatment across many persons. The real cost of the services is thus obscured because individuals seldom bear the costs directly or fully. This insulation of the individual patient from cost encourages the maximalist approach and supports the presumption that cost should not be a concern in the treatment of the patient. No matter how much is

11 Despite the enormous cost for very little return either in quality or length of life, there are strong pressures for intensive intervention on the individual basis even in the last days of life. 
spent on the patient, a large part of the payment will usually be made by the amorphous third-party payer.

As a result of all these factors, the United States has largely avoided making the difficult decisions regarding the distribution of scarce medical resources. Most often the "solutions" have merely shifted costs from the individual to the government (or vice versa), or from one third-party agent to another. Aaron and Schwartz, for instance, question the policy makers in the 1980s who relied on a shift toward prospective reimbursement schemes to solve health cost problems. ${ }^{12}$ Although giving the appearance of resolving the problem, these alterations only delay the need to make even harder choices in the future. These interim shifts in the burden of payment fail to deal with the critical issues of establishing policy priorities and setting limits on the use of high-cost medical technologies. To some extent, recent proposals for health care reform are misguided because they do not recognize that, no matter how we organize and fund the health care system, we cannot pay for the type of health care now expected by Americans. ${ }^{13}$ Unless policy makers are willing to take a stand and limit extravagant health care, the financial burden on future generations will escalate dangerously.

\section{Implications for Rationing Policy}

The belief that individuals have the right to unlimited medical care, the traditional acceptance of the maximalist approach by the medical community, and the insulation of the individual from feeling the cost of treatment, have placed severe limits on the extent to which proscription of expensive and often ineffective interven-

\footnotetext{
12 See Henry J. Aaron \& William B. Schwartz, The Painful Prescription: RATIONING HOSPITAL CARE 114-15 (1984).

${ }^{13}$ For a sampling of some of these proposals, see AMERICAN MEDICAL Ass'N, HEALTH ACCESS AMERICA: THE AMA PROPOSAL TO IMPROVE ACCESS TO AFFORDABLE, QUALITY HEALTH CARE (1991); NATIONAL LEADERSHIP COMM'N ON HEALTH CARE, FOR tHE HEALTH OF A NATION: A SHAREd RESPONSIBILITY (1989); THE PEPPER COMM'N, A CALL FOR AGTION (1990); and also see A NATIONAL HEALTH SYSTEM FOR AMERICA (Stuart M. Butler \& Edmund F. Haislmaier eds., 1989) [hereinafter NATIONAL HEALTH SYSTEM] (proposal by the Heritage Foundation); Ronald S. Bronow et al., The Physicians Who Care Plan: Preserving Quality and Equitability in American Medicine, 265 JAMA 2511 (1991) (proposals by Physicians Who Care); Rashi Fein, The Health Security Partnership: A Federal-State Universal Insurance and Cost-Containment Program, 265 JAMA 2555 (1991) (proposal by the Committee for National Health Insurance); and Birt Harvey, $A$ Proposal to Provide Health Insurance to All Children and All Pregnant Women, 323 NEW ENG. J. MED. 1216 (1990) (proposals by the American Academy of Pediatrics).
} 
tion is possible. Any limits on the rationing of medical technologies, therefore, must come from outside the health care system because there are no inbuilt limits, either in the public or the health care community. The only agent with the authority to influence public values and, thus, create a framework for setting limits, is the government.

Any rationing policy must take into account these multiple pressures from the providers and the consumers as well as the constraints imposed by demographic factors and the structure of the government itself. Many of the unique problems encountered in the United States can be traced to the absence of any single locus of power for making health care decisions and the fragmented, decentralized policy process. As long as there continues to be no one single accountable institution for making difficult choices, they will not be made in any systematic way.

Attempts to ration medicine by edict, particularly if they involve lifestyle changes, will be painful and acrimonious in a society that stresses the predominance of individual rights. Moderation of the expectations, demands, and behavior of a public that has come to expect unlimited access to technological progress in medicine will not be an easy task. As noted by David Mechanic, even though it may be that the public has developed unrealistic expectations, it is "unlikely that the American population would support the rationing of expensive high technology in the fashion characterizing England's National Health Service." 14 Moreover, because office holders gain no immediate political credit for trying to convince people that they are largely responsible for their own health problems, one can hardly expect most elected officials to publicly advocate an explicit rationing policy. Elections and careers are lost, not won, on such issues. Being called a visionary is little comfort to the official who loses reelection for advocating unpopular reforms. The difficulty of the issue, however, should not reduce the urgent need to face it.

A central element in any effort to ration medical resources in a fair and efficient manner is education designed to counter the technological imperative. Without a countervailing emphasis on the risks and dangers inherent in each proposed medical intervention, we will continue to embrace the technologies. Our failure to assess realistically the limits of medicine and the long-term consequences of high technology interventions and to communicate this assess-

14 DAVId MECHANIC, FROM AdVOCACY TO ALlOCATION: THE EVOLVING AMERICAN HEALTH CARE SYSTEM 215 (1986). 
ment to the public, produces a situation where intervention occurs first and serious contemplation of its advisability second, after the fact. ${ }^{15}$ Engelhardt and Rie are correct in their assertion that society must determine the point at which "undesirable" limits on health care are "simply unfortunate, but not unfair in the sense of constituting a claim on further resources. 16

The government has a responsibility to educate the public both as to the links between lifestyle choices and health, and the need to moderate expectations. This educative approach must be accompanied by a significant shift at the allocation level toward preventive and primary health care programs, which recently have received shrinking shares of the health care resources. ${ }^{17}$ This pursuit will be difficult, in part because of the momentum toward more profitable curative/rescue medicine and in part because of the strength of prevailing perceptions of health care. Unfortunately, high-technology interventions continue to receive more emphasis than does preventive education. ${ }^{18}$

The most controversial aspect of rationing medicine is the necessity of a shift toward individual responsibility for health status. Given the large proportion of health care expended on illnesses that are linked to lifestyle choice, ${ }^{19}$ however, any rationing policy, if it

15 The strong value bias in favor of technological fixes, combined with the inherent dramatic nature of many technological interventions, has led to a hesitancy by agencies charged with medical technology assessment to reject the technologies and recommend against their development and diffusion. See Robert H. Blank, The Limits of Biomedical Technology Assessment, in SCIENCE, TECHNOLOGY AND POLITICS: POLICY ANALYSIS IN CONGRESS 116 (Gary Bryner ed., forthcoming 1992); Harvard Community Health Plan, supra note 9, at 67 (stating that " $[\mathrm{n}]$ ewer, more expensive interventions are often adopted without systematic effort to determine whether the new technology is better than existing alternatives").

${ }^{16}$ H. Tristram Engelhardt \& Michael A. Rie, Intensive Care Units, Scarce Resources, and Conflicting Principles of Justice, 255 JAMA 1159, 1159 (1986).

17 See Daniel Callahan, What Kind of LifE: The Limits of MEdical Progress 264 (1990) (suggesting that the health care system should focus "on enhancing quality of life rather than holding off death, or on means of preventing illness and reducing the debilities of old age rather than on high-technology cures, or on enhancing the general level of public health rather than on the special curative needs of individuals").

${ }^{18}$ Ongoing decisions by many providers, including some states and Medicare, to fund heart and liver transplants indicate that forces against such a transformation are potent. Cf. J. Michael McGinnis, National Priorities in Disease Prevention, IssuEs ScI. \& TECH., Winter 1988-89, at 46, 49 (stating that "a leap forward in the ability to deliver preventive health services to individuals cannot happen without changes in the way Americans pay for health care" because the largest share of the huge sum spent on health care goes for treatment, not prevention).

${ }^{19}$ See Sullivan, supra note 8, at 1066 (noting that better control of fewer than ten 
is to be effective, must place considerable emphasis on the ultimate responsibility of the individual, not only for his or her own health, but also for reducing the overall costs to society. In the words of Louis Sullivan, "Health care professionals and policymakers need to create a climate of personal responsibility ... to establish fundamental, positive steps to help meet national goals." ${ }^{20}$ Only by creating this climate of personal responsibility can the following otherwise incompatible goals be achieved: increasing the span of healthy life, reducing disparities in health care among various population groups, and ensuring access to preventive services for all Americans.

More importantly, in an era of increasingly scarce resources where medical goods and services are rationed, the debate will intensify over the extent to which individual behavior ought to influence rationing decisions. Although the ethical controversy over this question will not abate, economic policy necessitates movement in that direction. According to philosopher $\mathrm{H}$. Tristram Engelhardt:

It will also be morally acceptable for a society, if it pursues expensive life-saving treatment, to exclude persons who through their own choices increase the cost of care... There is no invidious discrimination against persons in setting a limit to coverage or in precluding coverage if the costs are increased through free choice. ${ }^{21}$

Instillation of a future-oriented perspective both for individual health and societal survival is critical. Milbrath has noted: "There will be little meaning to political freedom, or freedom of choice, if our society fails to prepare for predictable crises . ..."22 Although the emphasis on individual responsibility for health does conflict with prevailing notions of free choice in a liberal society, failure to recognize the problem and take action now, even at the expense of some freedom of choice, risks the loss of considerably more freedom in the future. Mandatory constraints on the use of medical resources will increasingly result in decisions not to initiate

risk factors "could prevent between 40 and 70 percent of all premature deaths, a third of all cases of acute disability, and two-thirds of all cases of chronic disability"); see also McGinnis, supra note 18, at 46 (noting that, in contrast, "technologically oriented medical treatment currently promises to reduce premature morbidity and mortality by no more than perhaps 10 to 15 percent ${ }^{n}$ ).

${ }^{20}$ Sullivan, supra note 8 , at $1065-66$.

21 H. Tristram Engelhardt, Shattuck Lecture: Allocating Scarce Medical Resources and the Availability of Organ Transplantation, 311 NEW ENG. J. MED. 66, 70 (1984).

${ }^{22}$ MilbRATH, supra note 6 , at 301 . 
lifesaving treatment. Although such decisions have always been made, they have never been the product of an explicit rationing policy.

As stated earlier, the success of any effort to construct meaningful rationing policy hinges on our ability to moderate the expectations and demands of both the providers and users of health care. Although there are ways through which policy makers can influence the incentive structure and thus moderate expectations, in the end it is the consumers and providers who must realize that they are the keys to resolving the burgeoning health crisis. In a society that emphasizes self-gratification, materialistic values, and immediate pleasure, behavior changes necessary to improve health may be especially unpleasant and unsatisfying and, thereby, require considerable self-denial. Conversely, a healthy lifestyle might mean foregoing habits that are enjoyable to many people and largely viewed as critical components of free choice. ${ }^{23}$

This analysis illustrates the need for a collective, centralized initiative to shift the emphasis toward healthy lifestyles. Although individuals have some degree of freedom in such choices, the greater capacity to curb unhealthy habits and develop healthy ones lies at the societal level. At a minimum this requires placing the goal of health at least on par with that of enjoyment. To do this the incentive structure operating within society must be radically revised to better reward the healthful lifestyle choices of individual members; this can only be done through government intervention. A major part of this effort must be aimed at reducing the expectations of the public regarding the availability of health care resources and thereby reducing the unrealistic demand for unlimited use of curative medicine. Society must realize the necessity for limits and end the fatuous assumption of unlimited resources.

\section{Role of Providers IN Rationing}

Although the government alone has the means to initiate and coordinate necessary action, no health program can be successful without the support of physicians, hospitals, and other health care providers. Physicians, in particular, are key decision makers on the demand side of medicine: they serve as conduits for access to treatment regimens, technologies, and drugs. Relatively subjective

${ }^{23}$ It is especially difficult to convince young people to forego unhealthy pleasures when the potential benefits might not appear for many decades. 
decisions by physicians about patients' needs determine the demand for expensive intensive care treatment and tend to become institutionalized in the need formulas of hospitals and planning agencies. ${ }^{24}$ Any attempts by the government to require physicians to ration medical care on the grounds of societal rather than patient good conflicts with professional ethics and the traditional patientphysician relationship. ${ }^{25}$ Pellegrino argues that attempts to make the physician the designated guardian or gatekeeper of society's resources are "morally unsound and factually suspect." ${ }^{26}$ Similarly, physician Erich Loewy concludes that economic considerations as they affect either the patient, the hospital, or society are "not germane to ethical medical practice" and that "[i]t is dangerous to introduce extraneous factors into medical decisions." 27 Allen Dyer answers "an emphatic "No" to the question of whether the physician should be society's agent in reducing health costs and concludes that rationing decisions should not be made by doctors at the bedside, because their primary responsibility is to the patient, not to society. ${ }^{28}$

Despite these caveats, the medical profession increasingly will find itself in the uncomfortable position of responding to government initiatives and, eventually, regulatory pressures to systematize difficult rationing decisions. Although the shift toward public allocation is a clear threat to traditional medical ethics, Lundberg asks, rhetorically, how long physicians can continue to make such difficult policy judgments in response to short-term pressures. ${ }^{29}$ Can this piecemeal rationing process continue to dominate, in light of the extensive social investment riding on each decision?

Other observers contend that the medical profession must take responsibility for evaluating expensive new medical technologies and procedures prior to their being made available to consumers, since these prior allocation decisions "virtually always precede

${ }^{24}$ See Albert G. Mulley, The Allocation of Resources for Medical Intensive Care, in Securing Access to Health Care 285, 300 (President's Comm'n for the Study of Ethical Problems in Medicine and Biomedical and Behavioral Research ed., 1983).

${ }^{25}$ See Allen R. Dyer, Should Doctors Cut Costs at the Bedside?: Patients, Not Costs, Come First, 16 HASTINGS CENTER REP. 5,5 (1986) (stating that the emphasis on cost containment threatens the traditional doctor-patient relationship).

${ }^{26}$ Edmund D. Pellegrino, Rationing Health Care: The Ethics of Medical Gatekeeping, 2 J. CONTEMP. HEALTH L. \& POL'Y 23, 24 (1986).

27 Erich H. Loewy, Cost Should Not Be a Factor in Medical Care, 302 NEw ENG. J. MED. 697, 697 (1980).

${ }^{28}$ See Dyer, supra note 25, at 6.

${ }^{29}$ See George D. Lundberg, Rationing Human Life, 249 JAMA 2223, 2224 (1983). 
rationing decisions." ${ }^{30}$ Although Robert Veatch contends that the general public, not clinicians, ought to make allocation decisions, he points out that "[i]f cost containment is not on the clinicians' agenda, it would have to be on someone else's." 31 According to John Ashley: "Rationing is painful. Rationing does reduce costs by obviating the demand for allocation of resources. As our society demands that we avoid these costs, physicians should be intimately involved in the allocation and rationing decisions made both at the system and at the hospital level. ${ }^{\text {"32 }}$ Because of their crucial role as the point of access to health care, doctors must be active participants in the rationing of medical services. No longer do the health care providers automatically have a claim to all the societal resources they believe might benefit their patients, nor should they be able to make decisions without an awareness of the complex ramifications for the health care system as a whole. As uncomfortable as this shift is for the medical profession, it is already apparent (apart from any efforts at government involvement in the rationing of medical care) as evidenced by trends toward corporate health care, health maintenance organizations (and the increase of these organizations), and the increased rationing role of benefits managers for large employers.

\section{Failure of the Health Care MaRketPlace}

Many of the most vocal critics of the regulatory model of health care are those persons who favor continuation of the free enterprise, marketplace model. ${ }^{33}$ Fundamentally, they argue that the health care system is a large business and that, if left alone to operate according to the principles of supply and demand, it will best serve the consumer public. Regulation, it is contended, interferes with the effective operation of the marketplace and creates artificial inequities in the system.

${ }^{30}$ William A. Knaus, Rationing, Justice and the American Physician, 255 JAMA 1176, 1176 (1986).

$\$ 1$ Robert M. Veatch, DRGs and the Ethical Reallocation of Resources, 16 HASTINGS CENTER REP. 32, 38 (1986).

${ }^{32} \mathrm{John}$ T. Ashley, The Allocation and Rationing of High-Cost Services, 256 JAMA 350, 350 (1986).

${ }^{33}$ See, e.g., Jack A. Meyer, Health Care Policy: Historical Background and Recent Developments, in INCENTIVES vs. ConTrols IN HEALTH POLICY: BROAdENING THE DEBATE 8 (Jack A. Meyer ed., 1985) (presenting his view that "it is regulatory overkill for states to establish the rates at which all payers reimburse hospitals"). 
The fallacy of this approach is that the health care market contains none of the self-selecting mechanisms that work to check market excesses. In fact, if health care operated as a conventional market, "[w]e would be no more concerned about the proportion of the [GNP] consumed by health care than we [would] about the proportion of [GNP] spent on transportation, housing, or shoes. ${ }^{\text {"34 }}$ In order for an efficient, market-based health care system to work, several conditions are essential. First, decisions must be made by the consumers. Second, the consumers must know the value and costs of the goods they are contemplating purchasing. Third, the consumers must pay the full cost and receive the full value of the goods they choose to buy. All three conditions are absent from the current market for health care services. ${ }^{35}$

First, medical decisions are seldom made by the patient. Although some discretion is possible, the traditional physicianpatient relationship is based on the trust and ultimate dependence of the patient on the expertise of the physician, often under uncertain circumstances. The individual patient's choice is heavily conditioned and constrained by the providers of health care. Health care is not a commodity in any traditional market sense precisely because the patient cannot make his or her choice independent of these nonmarket forces.

Second, most patients have a difficult time judging the care they buy. As noted earlier, the health care providers have enormous discretion in deciding both the type and cost of care provided. ${ }^{36}$ The specialized knowledge required for the dispensation of health care, in conjunction with the emotional and often urgent nature of medical decisions, undercuts the patient's ability to be a rational shopper. It is unrealistic to expect consumers to become sophisticated, cost effective purchasers of health care, in part because of the steep learning curve in shopping for value in health care. ${ }^{37}$

${ }^{34}$ David M. Eddy, What Do We Do About Costs?, 264 JAMA 1161, 1165 (1990).

${ }^{35}$ See id.

${ }^{36}$ See supra text accompanying note 24.

37 Moreover, it does not follow that more informed consumers of health care will buy for lower cost. In fact, evidence suggests that knowledge often leads to higher costs because "[p]atients with more knowledge tend to be more demanding in terms of tests and treatments they want for themselves." DEAN C. CODDINGTON ET AL., THE CRISIS IN HEALTH CARE: COSTS, CHOICES, AND STRATEgIES 271 (1991). Demand for health care is inelastic for most consumers because an increase in price does not lead to significant decrease in the amount of services demanded. Patients want the best care regardless of cost and, when given a free choice, usually opt for the most technological and expensive form of health care. 
Third, the major reason that patients are unlikely to be frugal consumers, as assumed by marketplace models, results from the failure to meet the third condition. Third-party payment, whether private or public, assures that the potential consumer who receives the value pays only a fraction of the costs, if any. Under this incentive structure, it is "well known that people consume more when they do not pay the full cost of something than they would consume if they did pay the full cost." 38

Many proponents of market-based models would attempt to encourage consumer cost consciousness by either fine tuning (through increased co-payments, deductibles, etc.) or creating major alterations in the incentive structure. The Heritage Foundation proposal, for instance, shifts health care decision making to consumers through tax credits and a legal obligation on all families to obtain at least a minimum level of insurance protection. ${ }^{39}$ The proposal argues that " $[\mathrm{b}] \mathrm{y}$ purchasing their insurance themselves . . . Americans would become more sensitive to the cost of health insurance," and, thereby, more cost conscious. ${ }^{40}$ Enthoven and Kronick advance a less radical proposal that would have employees pay the difference between employer contributions ( 80 percent) and the cost of their chosen plan. ${ }^{41}$ Although Enthoven and Kronick are certainly correct in their contention that this incremental approach would be more compatible with American values than a publicly financed and administered model, its success would depend on the capacity to counteract Americans' heightened expectations for evermore expensive medical treatment and actually reduce costs.

We are past the point of incremental, piecemeal "solutions" to the health care crisis. The current market, a fragmented combination of private-public funding, is inequitable, inefficient, and costly. Recent studies have demonstrated that administrative costs of the present system are unconscionably high, particularly in the private sector. For example:

The U.S. government, much maligned for its inefficiency, does a far better job than commercial insurance companies when it comes

${ }^{38}$ Eddy, supra note 34, at 1169 .

${ }^{39}$ Stuart M. Butler \& Edmund F. Haislmaier, Introduction to NATIONAL HEALTH SYSTEM, supra note 13 , at $\mathrm{v}$, vii.

${ }^{40}$ Edmund F. Haislmaier, Health Care for Workers and Their Families, in NATIONAL HEALTH SYSTEM, supra note 13 , at $55,58$.

${ }^{41}$ See Alain Enthoven \& Richard Kronick, A Consumer-Choice Health Plan for the 1990s: Universal Health Insurance in a System Designed to Promote Quality and Economy (First of Two Parts), 320 NEw ENG. J. MED. 29, 32 (1989). 
to efficiently administering health care programs. ... If the private health insurance industry were as efficient as the U.S. Medicare system, consumers would save over $\$ 13$ billion each year. ${ }^{42}$

For every dollar the health insurance industry paid in claims in 1988 , it spent 33.5 cents for administration, marketing, and other overhead expenses. ${ }^{43}$ This is fourteen times higher than the 2.3 cents it cost Medicare to provide one dollar of benefits and eleven times higher than the 3.0 cents it cost the Canadian health system. ${ }^{44}$ Furthermore, between 1981 and 1988, these costs increased even faster than health care costs themselves. ${ }^{45}$

In addition to the administrative costs, a system with over 1500 different payers places severe burdens on providers, employers, and patients. Because each insurer has its own unique forms, administrative paper work consumes eighteen percent of an average hospital's budget, and has become a major cost for practitioners. ${ }^{46}$ Moreover, businesses are forced to employ fulltime health care administrators to manage coverage and health benefit consultants to find the most acceptable policies. The instability in the current payer system also forces employers to continually shop around for more affordable policies, resulting in a high annual turnover. ${ }^{47}$ These constant changes also present problems for the employees, who are often caught in the middle without coverage due to preexisting conditions and other inconsistencies between policies.

\section{SINGLe-PAYER, REgUlatory MODEL}

A single-payer plan available to all persons would dramatically simplify the processing of claims, reduce duplication of insurance monitoring or providers, and thereby rationalize a very confusing process for all parties. By spreading the risks across the entire population, a single-payer system would also eliminate cost shifting, a principle destabilizing factor and the "major culprit ultimately

42 Robert M. Brandon et al., Premiums Without Benefits: Waste and Inefficiency in the Commercial Health Insurance Industry, 21 INT'L J. HEALTH SERVICES 265, 276-77 (1991).

${ }^{43} \mathrm{See} i d$. at 272.

44 See id. at 276-77.

45 See id. at 267 (noting that overhead costs increased 93\%, while the increases in premiums sold was $73 \%$ and benefits paid was $77 \%$ ).

${ }^{46}$ See id. at 270.

${ }^{47}$ It has been estimated that one-third of all small businesses leave their insurance company or are not renewed each year. See id. 
behind the growing number of working uninsured Americans." 48 According to one study:

[W] have situations in which 60 to 70 percent of all patients, or more in some instances, are not paying the full price for services received. If the typical hospital is going to operate profitably, the remaining 30 to 40 percent of the patients served must pay premium rates high enough to cover those patients receiving services at discounts. ${ }^{49}$

This situation is patently unfair and further undermines the myth of a free market in the delivery of health care.

Opponents of a single-payer system argue that it is unworkable in our market-driven health system, takes away freedom to choose, stifles medical innovation, and is impossible to implement. ${ }^{50}$ It is also argued that such a system would be inequitable because only the wealthy would be able to escape its grasp by circumventing the system. ${ }^{51}$ Although the single-payer regulatory model would manifest all of these problems to some extent and is not a panacea, given the disequilibrium of the current system, it offers the best hope of a fair, equitable, and efficient approach to rationing. One commentator has noted "[c]urrent health policies have failed" and their continuation is certain to exacerbate an already bleak situation. ${ }^{52}$ As recent as a decade ago, the arguments of the opponents of the regulatory model would have had substantially more merit than they do today. We are now, however, "beginning to recognize the need for a deeper structural response to a world that is qualitatively different from what it was [then]. ${ }^{53}$ Crisis situations demand hard decisions and drastic action.

Given the unrealistic expectations and demands of the public, the intrinsically limitless capacity of medical progress to expand and escalate our definition of "need,"

48 CoDdINGTON ET AL., supra note 37, at 23.

${ }^{49} \mathrm{Id}$. at 36.

50 See Richard J. Arnould \&c Charles B. Van Vorst, Supply Responses to Market and Regulatory Forces in Health Care, in INCENTIVEs vs. Controls IN HEalth Policy: BROADENING THE DEBATE, supra note 33, at 107.

${ }^{51}$ See id. at 128.

52 Howard Waitzkin, Why It's Time for a National Health Program in the United States, 150 W.J. MED. 101, 106 (1989).

${ }^{53}$ Stephen M. Shortell \& Walter J. McNerney, Criteria and Guidelines for Reforming the U.S. Health Care System, 322 NEw ENG. J. MED. 463, 463 (1990).

54 See Daniel Callahan, Rationing Medical Progress: The Way to Affordable Health Care, 322 NEW ENG. J. MED. 1810, 1812 (1990) (stating that the definition of "need" is expanded in the pursuit of further progress to meet every human need). 
ed health care system to set limits, only a centralized authority will be able to make the hard, binding decisions that future rationing requires. Ironically, many of the persons who now argue against a regulatory model of rationing consistently have denied that any form of rationing is needed. Michael Reagan, for instance, contends that rationing really amounts to "income discrimination in the provision of health services" and argues instead for a strategy of "greater medical effectiveness." 55

Not surprisingly, many of the critics of the regulatory model point to the past failures of regulation, which, concededly, are numerous. Although the lack of a consistent, comprehensive, and rational regulatory effort is subject to valid criticism, the model itself is not. The United States has not had a prospective, futureoriented regulatory approach, but a patchwork, damage-control approach. Politics, not courage and anticipatory thinking, has been the central motivation in past regulatory efforts. The need for a fair and workable rationing policy now urgently requires vigorous, forceful, and bold national guidance. I agree with Davies and Felder who argue that "[i]ncreased health care rationing in the next decade is inevitable, yet it must not be done with quick fixes, shortterm solutions, and patchwork reform of our present system. That would create worse problems for health care in the 21st century ."56

There have been some optimistic signs that Congress is awakening to the problems discussed here. One component of the Senate Democrats' proposal was the emphasis on eliminating unnecessary medical procedures. ${ }^{57}$ Although the plan did not specify what this might include, it recommended setting national treatment guidelines for physicians and promoting the use of health maintenance organizations. Under the Democrats' proposal, a new federal agency would be created to set national health care spending targets and negotiate national hospital and physician rates. If all

55 Michael D. Reagan, Health Care Rationing and Cost Containment are Not Synonymous, 9 POL'Y STUD. REV. 219, 228 (1990).

${ }^{56}$ Nicholas E. Davies \& Louis H. Felder, Applying Brakes to the Runaway American Health Care System, 263 JAMA 73, 73 (1990).

57 This plan was drafted over a two-year period under the direction of Majority Leader George Mitchell and unveiled at a news conference on June 5, 1991. See Richard A. Knox, Senate Democrats Unveil Universal Health Care Plan, BOSTON GLOBE, June 6, 1991, at National/Foreign 1 (stating that nearly half of the projected savings under the plan would come from eliminating unnecessary medical care through stepped up doctors guidelines). 
parties to the negotiations, including providers and consumers, agreed to the rates, they would become binding. Although no reference was made to the concept of rationing per se, the relevance of this new agency to such efforts is significant.

More directly, Davies and Felder have proposed creation of "a national commission to study how best our nation can ration health care in the least onerous fashion in both the public and private sectors. ${ }^{58}$ This bipartisan commission "would be charged with looking globally at the American health care system, both in the short and the long terms, and ... righting the wrongs . . that have crept incrementally into the system during the past forty years. ${ }^{n 59}$ They argue that for national rationing of health care to be done fairly, there must be national guidelines-a national ethics policy that is defensible on grounds of consistency. ${ }^{60}$

The Canadian health care system has recently sparked considerable interest and debate as an alternative to explicit rationing that might be useful in the United States. The Physicians for a National Health Program, for example, has proposed a plan through which all Americans would be covered under a publicly administered, taxfinanced national health program. ${ }^{61}$ One single public payer in each state, locally controlled but subject to stringent national standards, would replace all the public and private insurers that now exist. This unitary administrative program, which has strong similarities to the Canadian system, would avowedly save tens of billions of dollars a year in administrative costs alone. More importantly, it would put into place the mechanism for a regulatory model of rationing.

In response to the criticism that moves to a single-payer system, with universal comprehensive coverage and a cost control situation similar to the Canadian system, would lead to unacceptable levels of conflict, Evans and his associates argue that while it might be harder to find the villain in the current U.S. system, "corporate competitors or employers may turn out to be more ruthless than public regulators." ${ }^{\text {Cost }}$ control, and certainly rationing, involve

58 Davies \& Felder, supra note 56, at 73.

${ }^{59} \mathrm{Id}$. at 74 .

${ }^{60}$ See id.

61 See Kevin Grumbach et al., Liberal Benefits, Conservative Spending: The Physicians for a National Health Program Proposal, 265 JAMA 2549, 2549 (1991) (proposing “a single, comprehensive public insurance program without co-payments or deductibles and with free choice of provider").

62 Robert G. Evans et al., Controlling Health Expenditures-The Canadian Reality, 320 
conflict between providers and payers in any system. Political processes focus this conflict, whereas market processes diffuse it, but do not necessarily reduce it. According to Evans, however, "the stylized political combat in Canada may result in less intrusion on the professional autonomy of the individual physician than is occurring in the United States. ${ }^{\text {69 }}$

Although the evidence on this contrast is not yet in, it is important because it shows that however rationing is carried out, conflict is inevitable. Moves toward a single-payer regulatory approach might initially be more painful and contentious, but in the long run, once the ground rules are established, it might be less stressful to the various parties. One of the complaints often heard among medical practitioners is that they could learn to live with a regulatory model if only the regulations were comprehensible, consistent, and stable, qualities now lacking throughout the health care system.

Whatever regulatory approach to rationing is implemented, Congress, with strong administrative support, will have to take action. There is presently strong support for some form of democratic approach to rationing, such as that being carried out in Oregon over the last several years. In addition, any regulatory strategy must ensure widespread public input at some stage. Because of the intense value bias in favor of technological fixes, individual rights, and life style choice, however, it is unlikely that the democratic model is appropriate for such a volatile issue as rationing. This does not preclude the need for an open, national dialogue, including all interested groups and individuals, detailing the desirable, broad social priorities. The idea that health policy, particularly rationing, should be made through referenda or other democratic mechanisms, however worthy it sounds, is infeasible.

Health care rationing might be one of those public issues that is best dealt with in negotiations outside of the public spotlight. Paul Light calls these issues, which usually involve cutting benefits or raising taxes, "dedistributive," and argues that they cannot be resolved in the public forum because they elicit insurmountable opposition from powerful interests on many sides. ${ }^{64}$ Light argues

NEW ENG. J. MED. 571, 576 (1989).

${ }^{63}$ Id. at 571.

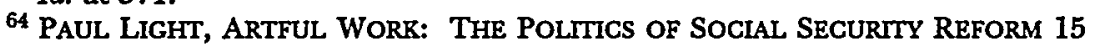
(1985) (stating that there is a great temptation to avoid action on dedistributive issues because of the electoral risks). 
that the opportunity for closed-door negotiation must be returned to Congress and advocates the use of bipartisan commissions for that purpose. ${ }^{65}$ Such commissions act mainly as fronts for secret bargains made between the President and congressional leaders and circumvent the need to debate and defend the various alternatives in public. Just as the Commission on Social Security Reform provided an opportunity to build a compromise, wrap it in a bipartisan flag, and drive it through Congress, so Congress might deal with the painful and politically explosive issue of rationing.

Although I have argued elsewhere against this approach as a means of legitimizing deception by government leaders, circumventing the democratic process, and being counter-productive in the long run, ${ }^{66}$ a multifaceted approach using a national commission to debate the question of social goals and priorities followed by a bipartisan commission to design the regulatory framework might now be appropriate. If an enlightened, authoritative, and highly visible national commission could ascertain societal health care goals, it would be politically more feasible to use a bipartisan commission to make the difficult political decisions that follow.

We must devise a rationing scheme that is industry-wide, not solely applicable to public programs. Unless rationing standards are uniform, the tiered system of health care will be solidified, thus reverting back to the current inequitable, inconsistent rationing approach. The assumption that the private sector will voluntarily conform to the lead of the public sector because the public sector represents forty percent of health care spending has been demonstrated to be fallacious by the institution of diagnosis-related groups (DRGs) in the $1980 \mathrm{~s}^{67}$

Furthermore, regulation will prove effective only if there are significant sanctions and penalties to conform to the established treatment standards. ${ }^{68}$ Physicians who knowingly exceed the standards by ordering unnecessary diagnostic tests and unapproved

65 See id. at 237.

${ }^{66}$ See BLANK, supra note 2, at 185.

${ }^{67}$ See CALlaHAN, supra note 17, at 78 (noting that the "DRG system has so far mainly shifted the costs from one sector to another, with no apparent net gain in savings").

${ }^{68}$ See Callahan, supra note 54, at 1811; see also A. Everette James et al., The Diffusion of Medical Technology: Free Enterprise and Regulatory Models in the U.S.A., 17 J. MED. ETHICS 150, 154 (1991) (agreeing that regulation is only effective with penalties, but that we must be cautious that the penalties do not compromise patient welfare). 
treatments bear the burden of proof for showing good reason for the breach of policy. This will force unpleasant choices and raise strong objections from health care providers initially, but if implemented in conjunction with a shift in public values toward a preventive/primary care strategy where equity is paramount, in the long run the current unfairness of market-based, decentralized rationing will be reduced.

\section{CONCLUSION}

An affluent society such as the United States should be able to provide good primary health care for all citizens, or at least for all citizens who make a minimal effort to reduce unwarranted health risks in their lives. Obviously, defining what this guaranteed primary health care should be depends on the resources available nationwide for health care. This, in turn, depends on the answer to two questions: how much money is society willing or capable of committing to health care? and what are our priorities for distribution of these funds so as to provide an equitable base of primary care for all citizens? Only after these decisions are made can we make reasonable choices as to how much we are willing to raise the level of health care. In other words, once we have met the goal of providing access to primary care on as equitable a basis as possible, any remaining funds should be used to expand the base and pursue ambitious life-extending programs.

Short of a fully single-payer national health system that guarantees access while providing strict incentives for the use of effective and cost-efficient health care services, a two-pronged strategy of value change and tightened regulation of protocol treatment is essential. First, we need a national education effort to instill the value of individual responsibility for health and convince the public that we must learn to live with a less expansive health care system and a less expansive idea of health. This national dialogue should include a thorough reevaluation of the current value system and the health care structure it has shaped. As a society, we must come to realize that in order to sustain a system with finite resources, we can no longer expect unlimited health care. The longer it takes to come to this realization, the more difficult rationing will ultimately be.

Second, we need to institute a centralized regulatory system of rationing scarce health care resources that addresses the long-term goals of equity, cost-containment, and accountability. Congress and 
the Administration have a duty to put aside their ideological baggage and work together with representatives of major private and public stakeholders to begin to fashion a workable mechanism for regulating the health care system. Likewise, the health care providers and private third-party payers have a responsibility to be active, constructive players in restructuring the health care system and shaping rationing regulations. The time for unmitigated selfinterest must yield to this broader social responsibility in time of crisis. Ideally, this rationing system would be administered under national guidelines by the states in cooperation with the powerful private sector. Realistically, a strong federal regulatory agency is needed to "motivate" compliance with national rationing standards that apply universally to the public and private sectors.

Although moves to this end initially are bound to ignite intense controversy, particularly in the medical marketplace, the heightening disaster in health care funding demands decisive action. If such action is not forthcoming, continuation of the status quo will lead to a "tyranny of our own making" through which we will "impoverish ourselves and successive generations by indulging in too much medicine. ${ }^{\text {69 }}$ A regulatory model will be difficult to implement and is unlikely to resolve the crisis by itself; nonetheless, the inability of the current allocation system to set limits necessitates vigorous governmental intervention.

${ }^{69}$ Carl J. Schramm, Can We Solve the Hospital-Cost Problem in Our Democracy?, 311 NEW ENG. J. MED. 729, 732 (1984). 